Case Report

\title{
Identification of Dietzia Species in a Patient with Endophthalmitis following Penetrating Injury with Retained Intraocular Metallic Foreign Body
}

\author{
Jesintha Navaratnam (D, ${ }^{1,2}$ Lumnije Dedi, ${ }^{3}$ Andreas Myklebust Tjølsen, ${ }^{4}$ \\ and Ragnheiður Bragadóttir ${ }^{1,2}$ \\ ${ }^{1}$ Department of Ophthalmology, Oslo University Hospital, Oslo, Norway \\ ${ }^{2}$ University of Oslo, Oslo, Norway \\ ${ }^{3}$ Department of Microbiology, Oslo University Hospital, Oslo, Norway \\ ${ }^{4}$ Department of Radiology, Vestfold Hospital Trust, Tønsberg, Norway
}

Correspondence should be addressed to Jesintha Navaratnam; jesintha.navaratnam@medisin.uio.no

Received 13 June 2018; Accepted 27 August 2018; Published 25 September 2018

Academic Editor: Gernot Walder

Copyright (c) 2018 Jesintha Navaratnam et al. This is an open access article distributed under the Creative Commons Attribution License, which permits unrestricted use, distribution, and reproduction in any medium, provided the original work is properly cited.

\begin{abstract}
To the best of our knowledge, we report the first case of Dietzia species in a patient with endophthalmitis. A 47-year-old man presented to the ophthalmology department with decreased vision, redness, and minimal pain in his right eye after a foreign body struck his eye following working using a hammer and chisel. Broad-spectrum polymerase chain reaction (PCR) and deoxyribonucleic acid (DNA) sequencing targeting $16 \mathrm{~S}$ ribosomal ribonucleic acid-(rRNA-) encoding gene on an undiluted vitreous sample revealed $100 \%$ identity with GenBank sequences of Dietzia species including D. natronolimnaea, D. dagingensis, and D. cercidiphylli. The culture of the vitreous samples demonstrated the growth of Gram-positive cocci and polymorphic rods. The isolate from the culture was identified as D. natronolimnaea using matrix-assisted laser desorption/ionisation time-of-flight mass spectrometry (MALDI-TOF MS). The combination of surgical and medical treatment (pars plana vitrectomy and systemic and topical antibiotics) eradicated the infection successfully.
\end{abstract}

\section{Introduction}

Infectious endophthalmitis is a sight-threatening infection. The incidence of infectious endophthalmitis varies between $0.0075 \%$ and $1.05 \%$ [1-9]. It can be further categorized into exogenous and endogenous types. If a distant source of infection spread hematogenously, it gives rise to endogenous endophthalmitis. The exogenous endophthalmitis represents the most common type of endophthalmitis and results from direct inoculation of an organism as a complication following ocular surgery, penetrating ocular trauma with or without retained foreign body, intravitreal injections of medications, or extension of corneal infection. Coagulasenegative staphylococci represent the most common pathogen in endophthalmitis following cataract surgery and intravitreal injections, and Bacillus cereus causes the most cases of endophthalmitis following trauma [10]. D. natronolimnaea is an aerobically growing Gram- and catalasepositive actinomycete. A case report involving $D$. natronolimnaea in human disease describes a case of culture negative device-associated endocarditis [11]. However, in this case, $D$. natronolimnaea could not be differentiated from D. cercidiphylli strain by DNA sequencing of the excised atrial tissue.

\section{Case Presentation}

A 47-year-old Norwegian male presented at the general causality clinic with right eye irritation. Previously, the same day he had been working using a hammer and chisel to repair his car without any eye protection, and he thought a foreign body had struck his right eye. The examination of his right eye revealed 
congestion and laceration of the conjunctiva, and the general practitioner started treatment with a broad-spectrum topical antibiotic (chloramphenicol). Seven days following his first presentation to the general causality clinic, he woke up with decreased vision, redness, and minimal pain in his right eye, and he presented to the nearby ophthalmology department on the same day. The best-corrected visual acuity (BCVA) decimal had decreased from 1.0 to 0.7 . The orbit computed tomography scans detected a metallic intraocular foreign body (Figure 1), and he was referred urgently to the Department of Ophthalmology at Oslo University Hospital for surgical removal of the foreign body. On arrival, the BCVA decimal had decreased from 0.7 to hand motion. The biomicroscopic examination revealed intense conjunctival and ciliary injection, most likely self-sealed conjunctival laceration, corneal oedema, 3+ anterior chamber cells with fibrin, and a thin layer of hypopyon in the anterior chamber and posterior synechiae. A layer of fibrin mesh covered the anterior surface of the lens. The changes in ocular media obscured the fundus view. The B-scan ultrasonography revealed an echogenic foreign body in the posterior vitreous cavity with dense vitreous opacities and attached retina and posterior vitreous. His left eye was unremarkable, and he was otherwise in good health. A clinical diagnosis of exogenous endophthalmitis secondary to penetrating eye injury with retained intraocular metallic foreign body was made.

He underwent an emergency 23-gauge pars plana vitrectomy with both undiluted and diluted vitreous biopsy and anterior chamber tap. The attempt to remove the intraocular foreign body was unsuccessful even after the removal of fibrin mesh layer covering the anterior surface of the lens due to poor surgical visualization of the posterior segment. At the end of the surgery, vancomycin $(1 \mathrm{mg} / 0.1 \mathrm{ml})$, ceftazidime $(2 \mathrm{mg} / 0.1 \mathrm{ml})$, and fungizone $(0.00549 \mathrm{mg} / 0.1 \mathrm{ml})$ were administered intravitreally and gentamicin $(20 \mathrm{mg} /$ $0.5 \mathrm{ml}$ ) subconjunctivally. He received treatment with topical steroids and antibiotics (Maxitrol eye drops consisting of dexamethasone, neomycin, and polymyxin B eye drops) hourly during daytime and intravenous cefuroxime $(750 \mathrm{mg}$ 3 times a day) postoperatively. In addition, he received oral steroids (prednisolone $60 \mathrm{mg}$ daily) only for 2 days prior to repeated pars plana vitrectomy. Due to poor visualization of the posterior segment initially, he underwent surgical removal of the metallic intraocular foreign body $(2 \times 1.5 \times 1$ millimetres) 7 days after the first operation. The day after surgical removal of the foreign body, the intravenous cefuroxime was discontinued, and he was prescribed a 10day course of ciprofloxacin (750 mg three times a day) peroral treatment. He continued with topical steroids and antibiotics (dexamethasone, neomycin, and polymyxin B eye drops) three times a day. The routine postoperative eye examination on the $9^{\text {th }}$ day following removal of the foreign body revealed asymptomatic rhegmatogenous retinal detachment from 10 to 2 o'clock with fovea on and with a BCVA decimal of 0.4 . He underwent his third pars plana vitrectomy with gas tamponade. Three weeks following the retinal detachment repair, he reached a BCVA decimal of 0.8 , and the retina was attached. Six months following the retinal detachment repair, he reached a BCVA decimal of 1.0.

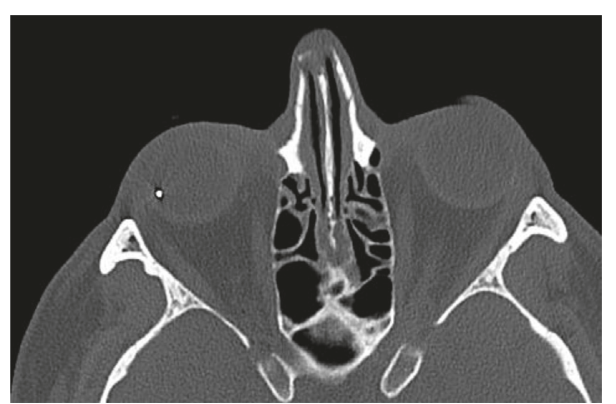

FIgURE 1: The computed tomography scan of the orbit demonstrates a metallic intraocular foreign body in the patient's right eye.

2.1. Microbiological Analysis. Direct microscopy of the undiluted vitreous sample showed pleomorphic rods with coccoid or club-shaped appearance suggesting coryneform bacteria.

A broad PCR and DNA sequencing targeting 16S rRNAencoding gene was performed on the undiluted vitreous body sample using EZI DNA tissue kit (Qiagen, Thermo Fisher Scientific, Hilden, Germany). The 5' half of the $16 \mathrm{~S}$ rRNA gene was amplified by PCR. The PCR product was sequenced using BigDye Terminator Cycle Sequencing Kit (Thermo Fisher Scientific, Hilden, Germany). The bacterium was identified by searching the GenBank (the NIH genetic sequence database) with the obtained DNA sequence. The obtained 740-base pair DNA sequence revealed 100\% identity with GenBank sequences of the Dietzia species including $D$. natronolimnaea, D. dagingensis, and D. cercidiphylli. Although, additional DNA sequencing on the rest of the 16S rRNA gene (total 1462 base pairs) was performed, and this did not give an unambiguous identification.

The undiluted and diluted vitreous samples were cultured on sheep blood agar and chocolate agar plates (Oslo University Hospital, Oslo, Norway). The plates were incubated at $35^{\circ} \mathrm{C}$ in $5 \%$ carbon dioxide $\left(\mathrm{CO}_{2}\right)$ for 7 days. The growth of bacteria was detected after two days under aerobic incubation at $35^{\circ} \mathrm{C}$ in $5 \% \mathrm{CO}_{2}$. Anaerobic culture using horse blood agar (Oslo University Hospital, Oslo, Norway) did not detect any bacterial growth, and yeast culture on Sabouraud agar (Oslo University Hospital, Oslo, Norway) did not reveal any growth. No bacterial or yeast growth was detected from the anterior chamber tap aspirate.

The Gram stain of the bacterial colonies demonstrated Gram-positive cocci and polymorphic rods. The isolate from the culture was identified as D. natronolimnaea using MALDI-TOF MS (MALDI Biotyper, Bruker Daltonics $\mathrm{GmbH}$, Bremen, Germany). MALDI-TOF was unable to distinguish $D$. natronolimnaea from $D$. dagingensis and $D$. cercidiphylli because the MALDI-TOF database does not contain the sequences for the latter two species.

Antimicrobial susceptibility tests were performed on Mueller-Hinton agar (Oslo University Hospital, Oslo, Norway) using MIC test strips (Liofilchem, Teramo, Italy). There are no determined breakpoints for Dietzia species, and therefore, the results were reported with a minimum inhibitory concentration (MIC) value. The MIC values of ciprofloxacin, gentamycin, tetracycline, and vancomycin 
against Dietzia species were low, indicating that these antibiotics have clinical effect.

\section{Discussion}

Rainey et al. proposed the new classification of genus Dietzia in 1995, and they suggested that Rhodococcus maris should be reclassified into a new genus, Dietzia [12]. The main natural reservoirs for Dietzia species include soil and marine sediments. D. natronolimnaea was first isolated from an East African soda lake in Kenya by Duckworth et al. [13]. The importance of recently established genus Dietzia in medical conditions in human is slowly emerging. $D$. maris has been reported as an etiological agent in a total number of three patients. They presented with prosthetic hip infection [14], septicaemia [15], and aortic dissection secondary to aortitis [16]. This strain has also been detected from the skin of healthy individuals [17]. The strain $D$. cinnamea has been isolated from a perianal swab in a patient with bone marrow transplantation [18] and from a dog bite wound in an adult patient [19]. The authors in both case reports questioned the potential of $D$. cinnamea to cause infection. Jones et al. isolated $D$. papillomatosis from an immunocompromised patient with confluent and reticulated papillomatosis, which is a benign skin disorder [20]. Rammer et al. identified $D$. papillomatosis in blood culture in a 2 -year-old child who presented with fever following revision of ventriculoperitoneal shunt inserted as treatment for syringomyelia [21]. Furthermore, Dietzia species has been isolated repeatedly in a hematological unit in the United Kingdom [22]. At present, the only report of $D$. aurantiaca from human clinical specimens is from a 24-year-old Swedish woman's cerebrospinal fluid [23]. In another case, an 87-year-old man developed cellulitis-like inflammation 10 months following permanent pacemaker insertion, and Dietzia species were detected [24]. The authors in the culture negative deviceassociated endocarditis involving $D$. natronolimnaea stated that the DNA sequence from the excised atrial tissue of the patient revealed D. natronolimnaea that shared $100 \%$ identity with $D$. cercidiphylli strain. Very few case reports describe identification of Dietzia species in human conditions. However, their role in causing infection should be elucidated in the future.

The identification of the infecting organism in exogenous endophthalmitis may be challenging. In a study from which bacteriologic data were obtained from postoperative endophthalmitis cases, only 291 out of 420 patients $(69.3 \%)$ demonstrated microbial growth. [25] In this study, Grampositive bacteria were isolated in 274 patients (94.2\%).

The similarities in the Gram morphology and colony appearance displayed by Dietzia species and the more frequently encountered Rhodococcus species may lead to misinterpretation of Dietzia species as Rhodococcus species. This may implicate the underdiagnosis of Dietzia speciesrelated infections in humans. Additionally, D. natronolimnaea may easily be missed, if cultured less than 72 hours and at incubation temperature at or above $37^{\circ} \mathrm{C}$. The growth occurs at $\mathrm{pH}$ 6-10 with optimal growth at $\mathrm{pH} 9$ and at salt concentrations up to $10 \%$ [22]. Previously, the diagnosis of
Dietzia species may have been challenging due to the lack of accurate diagnostic tests. Although the DNA sequencing of $16 \mathrm{~S}$ rRNA encoding gene assists in precise determination of species, some of the Dietzia species share $100 \%$ gene identity. In the patient described in this case report, the DNA sequencing of $16 \mathrm{~S}$ rRNA encoding gene revealed $100 \%$ identity with GenBank sequences of D. natronolimnaea, D. dagingensis, and D. cercidiphylli. Similarly, Sudhindra et al. could not distinguish between the former two Dietzia species. The unique characteristic of mycolic acids in Dietzia may indicate a novel fatty biosynthesis [26]. This may aid in development of new accurate diagnostic laboratory tests. In future, increased awareness and development of accurate tests may assist in the diagnosis of Dietzia species infections.

\section{Conflicts of Interest}

The authors declare that there are no conflicts of interest.

\section{Acknowledgments}

The authors are grateful for the patient who gave his consent to publish this case report. The authors would like to thank physicians at the Department of Ophthalmology at Tønsberg Hospital (Vestfold Hospital Trust) for providing with follow-up details of the patient.

\section{References}

[1] K. Xu, E. K. Chin, S. R. Bennett et al., "Endophthalmitis after intravitreal injection of vascular endothelial growth factor inhibitors: management and visual outcomes," Ophthalmology, vol. 125, no. 8, pp. 1279-1286, 2018.

[2] H. Casparis, T. J. Wolfensberger, M. Becker et al., "Incidence of presumed endophthalmitis after intravitreal injection performed in the operating room: a retrospective multicenter study," Retina, vol. 34, no. 1, pp. 12-17, 2014.

[3] T. Inoue, T. Uno, N. Usui, S. Kobayakawa, K. Ichihara, and Y. Ohashi, "Incidence of endophthalmitis and the perioperative practices of cataract surgery in Japan: Japanese prospective multicenter study for postoperative endophthalmitis after cataract surgery," Japanese Journal of Ophthalmology, vol. 62, no. 1, pp. 24-30, 2018.

[4] E. Friling, M. Lundstrom, U. Stenevi, and P. Montan, "Sixyear incidence of endophthalmitis after cataract surgery: Swedish national study," Journal of Cataract and Refractive Surgery, vol. 39, no. 1, pp. 15-21, 2013.

[5] M. Raen, G. F. Sandvik, and L. Drolsum, "Endophthalmitis following cataract surgery: the role of prophylactic postoperative chloramphenicol eye drops," Acta Ophthalmologica, vol. 91, no. 2, pp. 118-122, 2013.

[6] K. U. Sandvig and L. Dannevig, "Postoperative endophthalmitis: establishment and results of a national registry," Journal of Cataract and Refractive Surgery, vol. 29, no. 7, pp. 1273-1280, 2003.

[7] T. A. Meredith, C. A. McCannel, C. Barr et al., "Postinjection endophthalmitis in the comparison of age-related macular degeneration treatments trials (CATT)," Ophthalmology, vol. 122 , no. 4 , pp. 817-821, 2015.

[8] J. B. Fileta, I. U. Scott, and H. W. Flynn Jr., "Meta-analysis of infectious endophthalmitis after intravitreal injection of anti- 
vascular endothelial growth factor agents," Ophthalmic Surgery, Lasers and Imaging Retina, vol. 45, no. 2, pp. 143-149, 2014.

[9] D. T. Du, A. Wagoner, S. B. Barone et al., "Incidence of endophthalmitis after corneal transplant or cataract surgery in a medicare population," Ophthalmology, vol. 121, no. 1, pp. 290-298, 2014.

[10] M. L. Durand, "Endophthalmitis," Clinical Microbiology and Infection, vol. 19, no. 3, pp. 227-234, 2013.

[11] P. Sudhindra, G. Wang, and R. B. Nadelman, "Identification of Dietzia spp. from cardiac tissue by $16 \mathrm{~S}$ rRNA PCR in a patient with culture-negative device-associated endocarditis: a case report and review of the literature," Case Reports in Infectious Diseases, vol. 2016, Article ID 8935052, 5 pages, 2016.

[12] F. A. Rainey, S. Klatte, R. M. Kroppenstedt, and E. Stackebrandt, "Dietzia a new genus including Dietzia maris comb. nov., formerly Rhodococcus maris," International Journal of Systematic Bacteriology, vol. 45, no. 1, pp. 32-36, 1995.

[13] A. W. Duckworth, S. Grant, W. D. Grant, B. E. Jones, and D. Meijer, "Dietzia natronolimnaios sp. nov., a new member of the genus Dietzia isolated from an East African soda lake," Extremophiles, vol. 2, no. 3, pp. 359-366, 1998.

[14] O. Pidoux, J. N. Argenson, V. Jacomo, and M. Drancourt, "Molecular identification of a Dietzia maris hip prosthesis infection isolate," Journal of Clinical Microbiology, vol. 39, no. 7, pp. 2634-2636, 2001.

[15] P. Bemer-Melchior, A. Haloun, P. Riegel, and H. B. Drugeon, "Bacteremia due to Dietzia maris in an immunocompromised patient," Clinical Infectious Diseases, vol. 29, no. 5, pp. 1338-1340, 1999.

[16] G. Reyes, J. L. Navarro, C. Gamallo, and M. C. delas Cuevas, "Type A aortic dissection associated with Dietzia maris," Interactive CardioVascular and Thoracic Surgery, vol. 5, no. 5, pp. 666-668, 2006.

[17] I. Dekio, M. Sakamoto, H. Hayashi, M. Amagai, M. Suematsu, and Y. Benno, "Characterization of skin microbiota in patients with atopic dermatitis and in normal subjects using 16S rRNA gene-based comprehensive analysis," Journal of Medical Microbiology, vol. 56, no. 12, pp. 1675-1683, 2007.

[18] A. F. Yassin, H. Hupfer, and K. P. Schaal, "Dietzia cinnamea sp. nov., a novel species isolated from a perianal swab of a patient with a bone marrow transplant," International Journal of Systematic and Evolutionary Microbiology, vol. 56, no. 3, pp. 641-645, 2006.

[19] J. J. Hirvonen, I. Lepisto, S. Mero, and S. S. Kaukoranta, "First isolation of Dietzia cinnamea from a dog bite wound in an adult patient," Journal of Clinical Microbiology, vol. 50, no. 12, pp. 4163-4165, 2012.

[20] A. L. Jones, R. J. Koerner, S. Natarajan, J. D. Perry, and M. Goodfellow, "Dietzia papillomatosis sp. nov., a novel actinomycete isolated from the skin of an immunocompetent patient with confluent and reticulated papillomatosis," International Journal of Systematic and Evolutionary Microbiology, vol. 58, no. 1, pp. 68-72, 2008.

[21] P. Rammer, H. Calum, C. Moser et al., "Dietzia papillomatosis bacteremia," Journal of Clinical Microbiology, vol. 51, no. 6, pp. 1977-1978, 2013.

[22] R. J. Koerner, M. Goodfellow, and A. L. Jones, "The genus Dietzia: a new home for some known and emerging opportunist pathogens," FEMS Immunology and Medical Microbiology, vol. 55, no. 3, pp. 296-305, 2009.
[23] P. Kampfer, E. Falsen, A. Frischmann, and H. J. Busse, "Dietzia aurantiaca sp. nov., isolated from a human clinical specimen," International Journal of Systematic and Evolutionary Microbiology, vol. 62, no. 3, pp. 484-488, 2012.

[24] S. Perkin, A. Wilson, D. Walker, and E. McWilliams, "Dietzia species pacemaker pocket infection: an unusual organism in human infections," BMJ Case Reports, vol. 2012, 2012.

[25] D. P. Han, S. R. Wisniewski, L. A. Wilson et al., "Spectrum and susceptibilities of microbiologic isolates in the endophthalmitis vitrectomy study," American Journal of Ophthalmology, vol. 122, no. 1, pp. 1-17, 1996.

[26] Y. Nishiuchi, T. Baba, and I. Yano, "Mycolic acids from Rhodococcus, Gordonia, and Dietzia," Journal of Microbiological Methods, vol. 40, no. 1, pp. 1-9, 2000. 


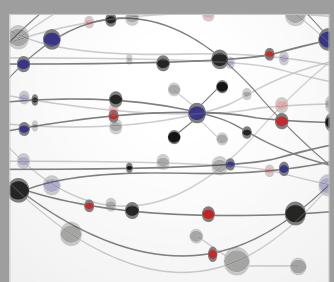

The Scientific World Journal
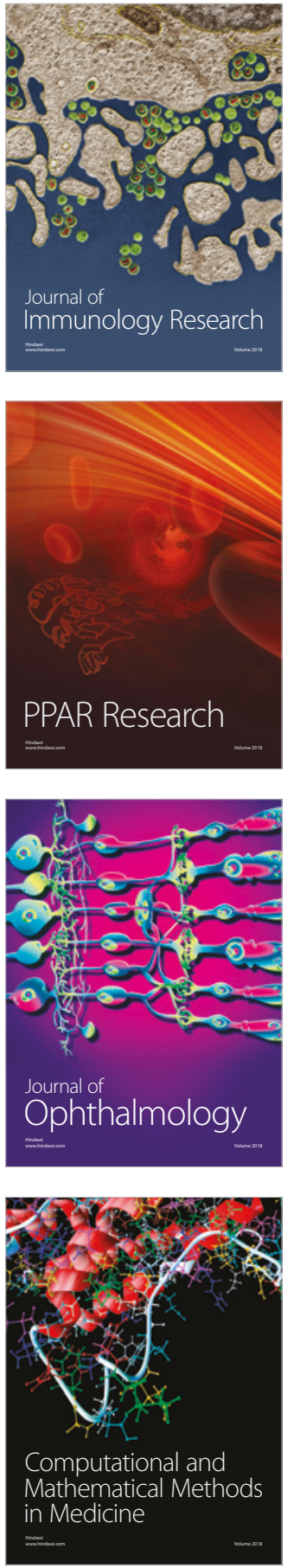

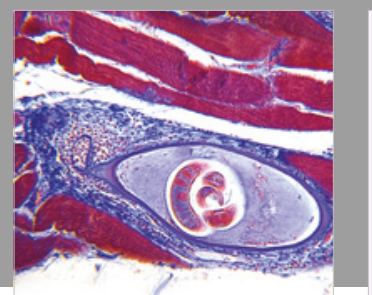

Gastroenterology Research and Practice

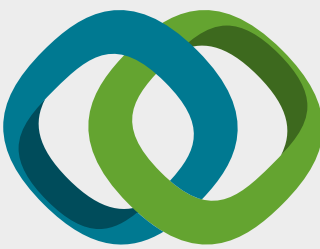

\section{Hindawi}

Submit your manuscripts at

www.hindawi.com
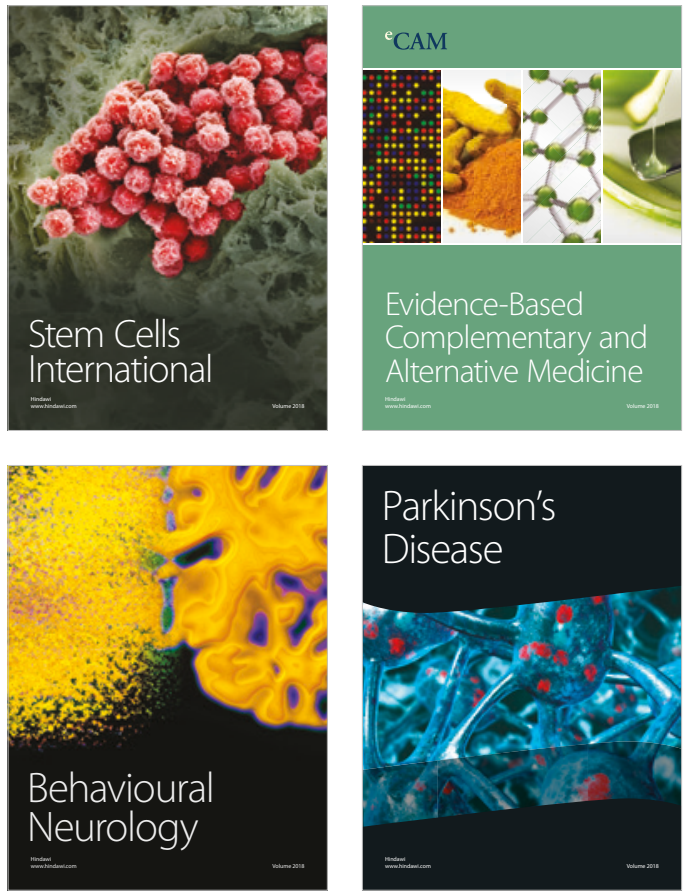

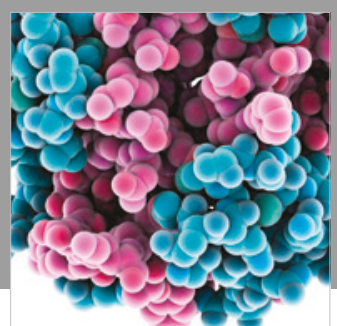

ournal of

Diabetes Research

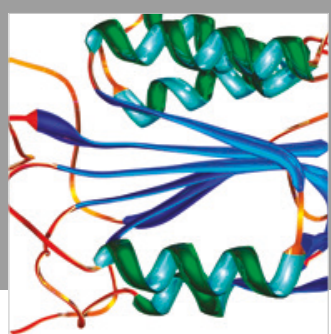

Disease Markers
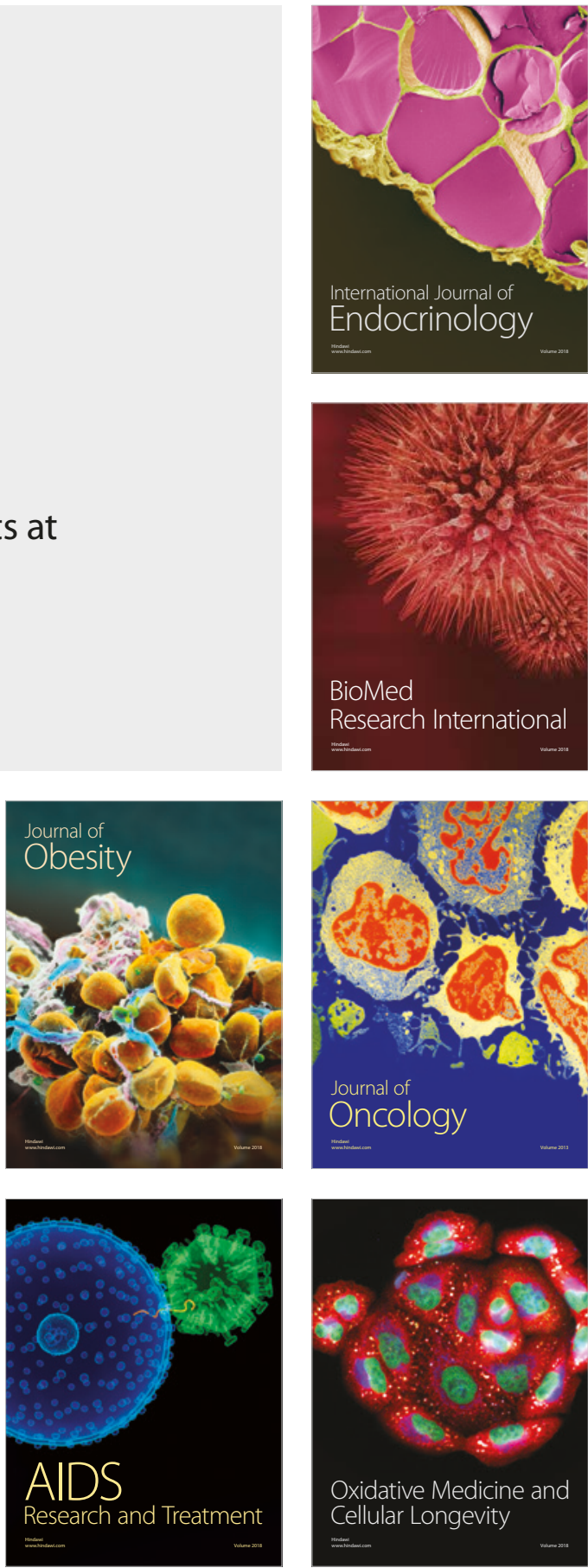